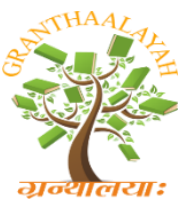

INTERNATIONAL JOURNAL OF RESEARCH GRANTHAALAYAH A knowledge Repository

Science

\title{
SUSTAINABILITY THROUGH LOW COST TECHNIQUES IN INDIA (CHANNELIZING WORKS INFLUENCED BY ARCHITECTS)
}

\author{
Ar. Manita Saxena *1, Ms. Shruti Sharma ${ }^{2}$ \\ ${ }^{* 1}$ Professor SOA IPS Academy, SOA Academy Indore, India \\ ${ }^{2}$ Final Year B.Arch. SOA Academy Indore, India
}

DOI: https://doi.org/10.29121/granthaalayah.v5.i2.2017.1700

\begin{abstract}
"Sustainability through low cost housing" is a study based on some architects works of low-cost housing and there influences on architecture. Sustainable and low-cost is now a trend in architecture, there are many of the projects which are truly based on low cost techniques which was used by Sir Ar. Laurie baker and some architects still working on it. Study is to lighten up the latest techniques which they used in their projects, and his principles and selection of materials. Now a day, people think urban and a lavish life style, with affordable and eco logical friendly living.

COSTFORD, is a bigger name in this field of low cost housing, where they are working on lowcost and providing lavish and wonderful places for their clients, and one more new organization are there "GOODEARTH" they are working on sustainability with their designing approaches and techniques.
\end{abstract}

Keywords: Channelizing Works; Architects; Sustainability.

CITE THIS ARTICLE: Ar. Manita Saxena, and Ms. Shruti Sharma. (2017). "SUSTAINABILITY THROUGH LOW COST TECHNIQUES IN INDIA." International Journal of Research - Granthaalayah, 5(2), 31-38.

\section{Introduction}

The study aims at sustainability of low-cost works of different architects through, their principles of cost reduction and techniques. We have some specialize architects working on low cost housing, hence research focus on sustainability of low cost housing came through contribution of Indian Ar. Laurie baker who later known as "Gandhi of low cost housing" some of them trained under worked with Laurie baker and are influenced by his low-cost housing techniques. And some of them are architects working on low cost housing techniques. 


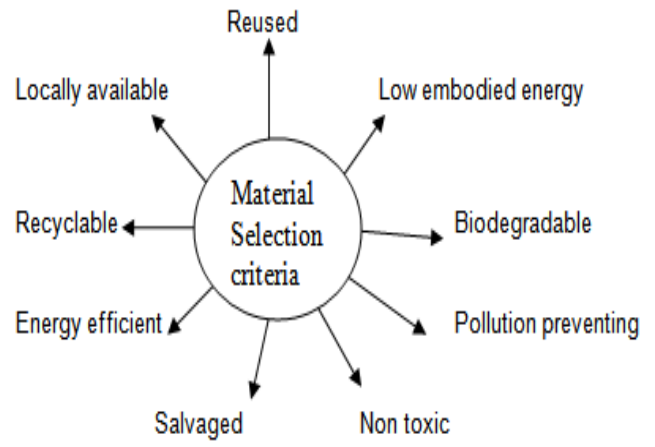

Research Questions: What is the extent of influence of low cost housing on architects in India? What is this influence? Is it for commercial purpose or the genuine reasons like providing basic shelter in the homeless, or is it used for cost reduction?

The research would analyses for: Influence mostly in institutions and low cost projects. If time permits, a study of other individuals influenced by either Laurie baker or these architects which would be an indirect influence of Laurie baker, could be pursued.

Scope and Limitation's: This reason will be limited to the study of basic architectural principles the spatial quality, the techniques and the materials employed and the influences on the final cost. The work of five architects will be analyzed.

Methodology: first part includes introduction and life influences of baker. And second part includes architectural scenario of India, then third part of research includes influenced architects and there works. Then conclusion.

Literature Review: The first part of the research on Laurie Baker involved most of the literature survey. The three books which formed the core of the research were: - (1) Laurie Baker: Life, work, writing by Bhatia, (1991). 2) The other side of Laurie Baker by Baker, E. (2007). (3) Architecture and Urbanism, Feature: Laurie Baker by Plummer, (1995).

\section{Influences}

\section{What is the extent of influence of Laurie baker for low cost housing India ?}
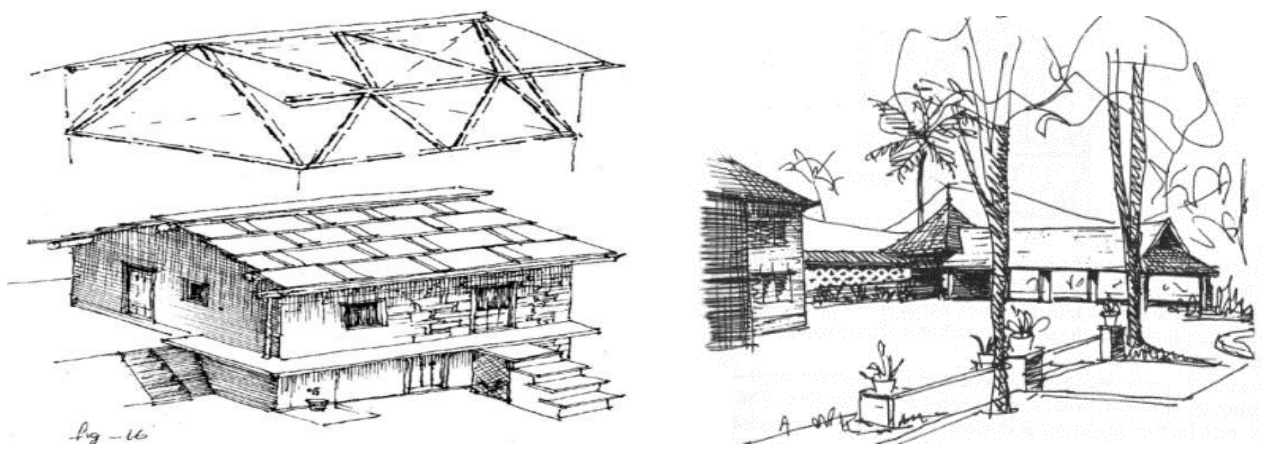
"his works is becoming increasingly influential, not only in India but throughout the world, as it receives more publicity (Spence 1980) baker 1984, 1990, Bhatia 1994). Born on March 2, 1917 and brought $\mathrm{u}$ in Birmingham England, Laurence Wilfred (Laurie) baker (1917-2007) was the son of staunch and faithful methazoles parents. In 1945 he came across 'The mission to lepers' Organization which was in a great need of an architect or builder to come to India and build new modern hospitals, baker had immediately made up his mind to take up this job and build homes and hospital for the lepers.

\section{Architecture in India}

Post-Independence Scenario In India: During the British rule in India, colonial architecture had been introduced throughout the major cities across the country. Post-dependency India needed an identity. As this time Europe was experiencing tremendous growth in the industries and was experiencing tremendous growth in the industry and was approaching modernism. The item prime minister, Jawaharlal Nehru employed architect Le Corbusier to design the attempts at creating an identify by almost forgetting to consider the part heritage of the country.

Vernacular Architecture in India: The local architecture in India is diverse in terms of types. Architectural elements like the internal courtyards, veranda's, pitched roofs, mud or masonry seats, etc. Are commonly observed through the hierarchy. The arrival of the Portuguese in the 16th century introduced European ideas to the local architecture of the place. The resulted in the Portuguese started off by building churches, converts and palatial mansions. This brought about a whole new perspective in the scale factor of the local architecture.

Current Scene in Architecture: In the current scenario Architecture is a wide practice of all different sorts of beliefs and phenomena. Unlike vernacular architecture, the modern trends are oriented towards "fashion statements" and often logic and values are non-existent. It is highly chaotic and reflects thought schools from all over the world, regardless of the unique geographical, climatic, social and cultural context.

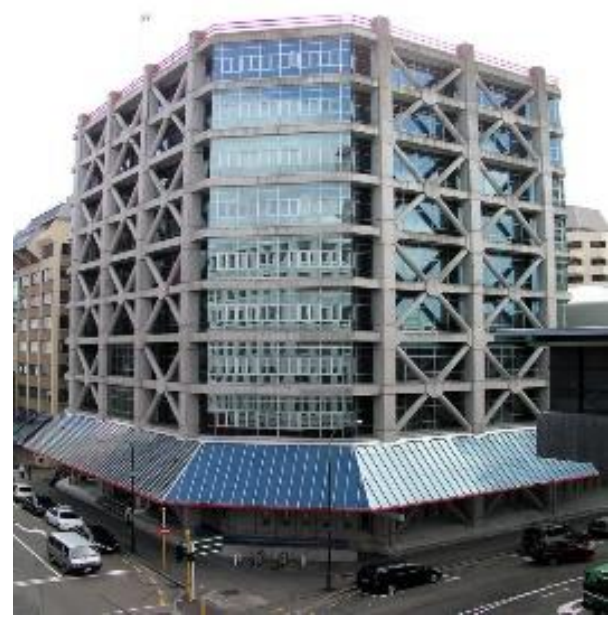


'Facadism' Is the Replacement For Architecture: All sorts of materials are used to clad a structure to achieve the 'look', stone cladding for a 'natural look', or sometimes even for the 'sustainable look'. In this lost world, very few architects are concerned about depleting natural resources, issues of conservation of energy, the carbon foot print of the built environment and other related issues, Of the few concerned architects, some have been inspired or at some point have looked at baker for his philosophy, practice and works.

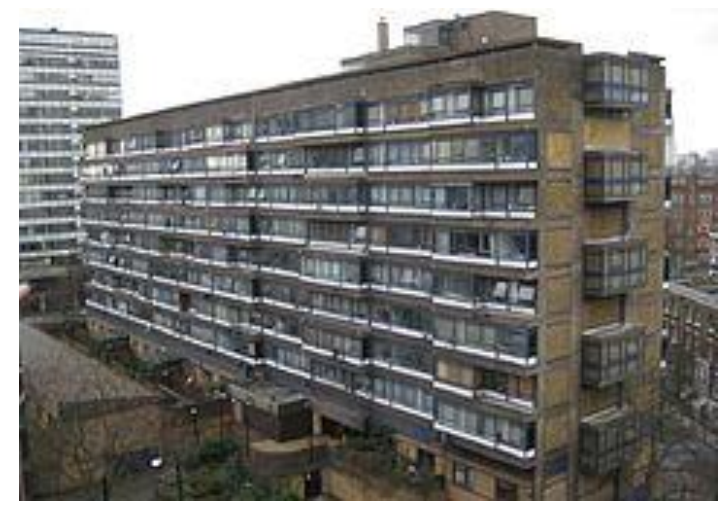

\section{Architects Influenced by Sustainable and Low Cost Housing}

The following is the list of architects practicing in south of India and some are influenced by baker's work of low cost housing, who have been inspired by baker:

1) Ar. Gerard da cunha

2) Ar. Ramesha bandekar

3) Ar. Habeeb khan

4) Ar. Himanshu burte

5) Ar. Mohsen Mostafavi

6) COSTFORD,

7) LAURIEBAKER CENTRE OF DEVELOPMENT AND STUDIES.

8) GOODEARTH (building sustainable communities.) "To create a society, that is environmentally sensitive, economically sensible and socially secure. "The above list was derived through discussion's, suggestions and interview with the same. There could be one or more architects who have been missed out.

Criteria for Selection of Architects for Analysis: The architects were selected based on the following points: - Worked with Laurie baker, inspired by baker's practice in low cost, Inspired by baker's ideology. Working with local materials / techniques, genuinely practice sustainability and low cost housing.

\section{Description of Their Work}

What is this influence is it for commercial purpose or the genuine reasons like providing basic shelter in the homeless, or is it used for cost reduction? 
Since Baker has been well known for his values and practice, hence architects with a similar approach or view point have looked up to his work and practice. Only one of the architects mentioned in the list have worked with or under baker. The motive of sir baker is not only providing shelter but he used to make appropriate designs according to his client's needs, and also had a focus on their client's budget, according to their needs and there proper budget.

\section{Inferences of Baker Through Low Cost}

Design Principles: Baker believed in applying vernacular principles to modern construction technology. He mentioned that we need to take forward by adding modern technology to that which has already been accomplished by our ancestors and contribute to it instead of contradicting it.

Plan Form and Structural Form: Baker in his own words said, "Always living close to nature, learn many lessons from the design of god's creations. Very rarely do we find the square or rectangle but very often the circle is used. The straight line is rare, but the graceful curve is frequently seen, interesting scientific observation is that the length of the wall enclosing given area is shorter if the shape is circular and longer if the shape around the same area is a rectangle.

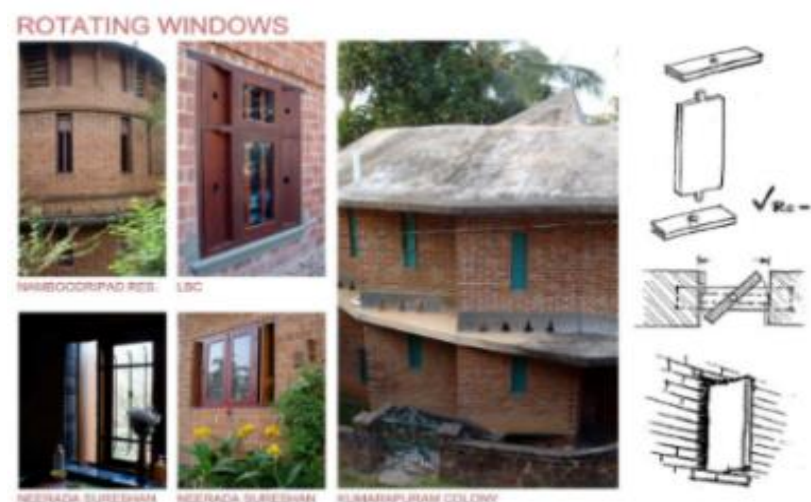

Materials Used: Natural locally available materials were preferred over modern materials. These included materials like brick which were locally made. The choice of these materials stemmed out from the need to be honest and use minimal energy.

Techniques Employed: Baker used techniques observed by improving on them, he applied vernacular principles to modern construction techniques, as the traditional methods often had apt solutions to current day problems faced in construction.

Labour Employed: He himself participated in the construction process, enacting the role of a designer, builder and contractors simultaneously. He worked with a small of masons and contractors trained by him. Traditionally construction was carried out by craftsman, this practice has been appreciated by baker in his practice as well. There is the issue of unemployment in India, training locals as masons or even site helpers helped solve the issue. 


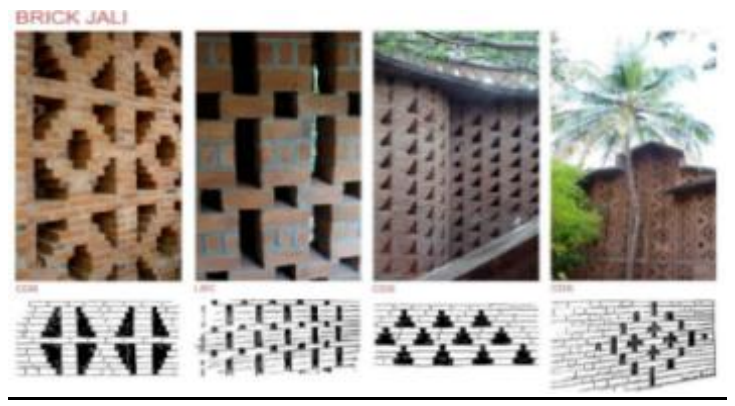

Elements and Measures Taken for Cost Reduction: Every step taken in the whole process of designing and executing a project was a conscious one towards.

\section{Conservation of Resources and Energy, in Turn Reducing the Cost}

1) Use of jallis for light and ventilation instead of windows.

2) Filler slabs to reduce reinforcement.

3) Curved walls instead of square or rectangles.

4) Sewage materials, door, window frames.

5) In built furniture's.

6) Use of local materials. The way Baker practiced, wherein he himself was the builder and contractor saved finance of clients.

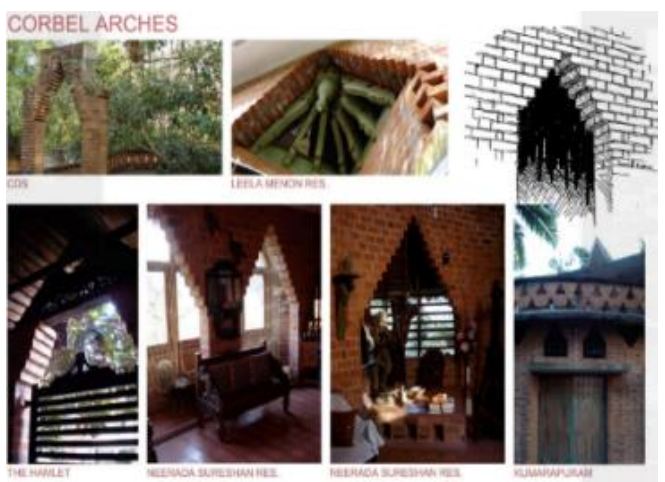

\section{Summary of Architectural Principles}

Baker followed a set of simple principles in his life as well as his architectural practice. Based on his notes, writings, and the literature surveyed, baker's philosophy can be summarized as follows:

1) Use of local materials

2) Employment of local techniques

3) Labour involved (local / architect's team)

4) Cost effectiveness of the projects.

5) Plan form of the structure

6) Minimal energy use

7) Site response 


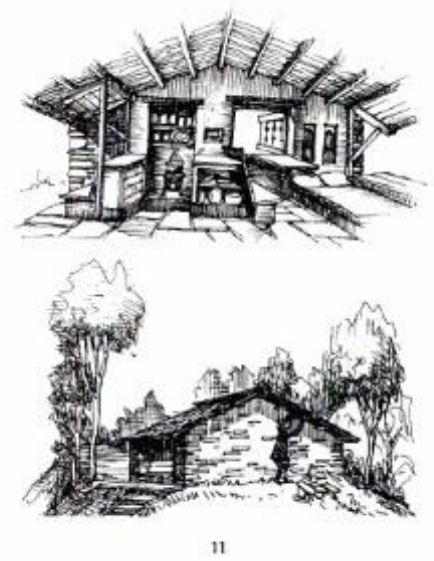

\section{Inferences from Gerard Da Cunha's Work's}

Design Approach: The architect attempts to make the best of each site and projects by having an innovative approach to design and creative executing it. The focus of some projects revolves around cost reduction, hence influencing major decisions.

Plan Form and Structural Form: In some cases, the architecture used a lot of curved walls which provide structural forms generated by using shapes forms and elements forms a limited palate. The use of conventional and unconventional mix of openings adds to the unique forms.

Elements and Measures Taken for Cost Reduction: Spiral staircase, Exposed walls, arched openings Salvaged or reused materials.

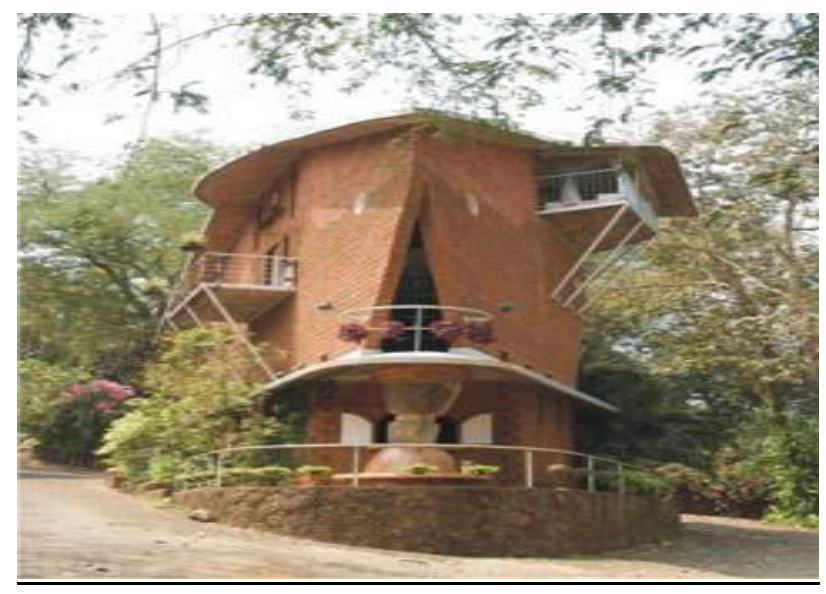

\section{COSTFORD}

- A Sustainable Approach to Slum Redevelopment: The Karimadom Colony

- A township coming up at Kalladimugham in Thiruvananthapuram

- The projects get the HUDCO Design Awards for being environment-friendly and costeffective. 


\section{Conclusion}

One strong chord that held together his Architecture did not spring from sentimentalism but came from a need or a set of requirement, often the bare essentials. This is observed in the use of curve. Baker used the curved wall because the length of a curved wall enclosing a specific area is less compared to the length a square or a rectangle would take to enclose the same given area. Often a curve is used with the need of define a space in a warmer manner, and not really for its practical aspect. Choice of client plays a major role in the architecture generated. Baker was approached by clients who needed affordable by clients who needed affordable homes. On the contrary the Architect who have been influence by Baker are approached for a 'Baker Style home' and not so often for a home which costs little. But now a day through his contribution, it is in a latest trend of low-cost and sustainable housing.

Time factor: The need of quick completion of project directs one towards factory produced architectural solutions. Other influences on architect personal beliefs past experiences work experiences with other architects etc. The difference between the work of architect like Laurie baker, nariman Gandhi, the Australian architect Glen Murcutts and few others who have practiced architecture with a great sense of responsibility towards nature and humanity itself is the value system they have followed.

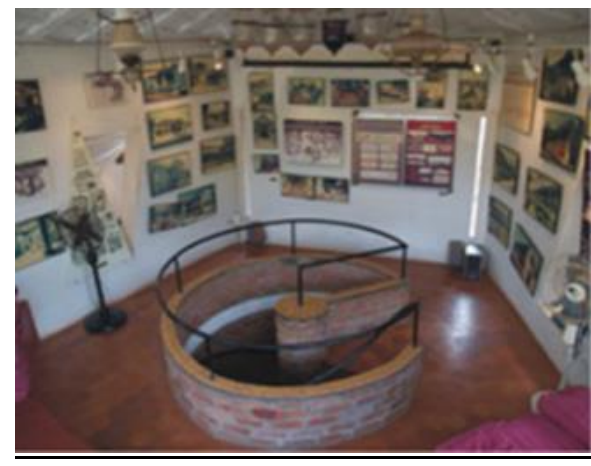

\section{References}

[1] Laurie Baker's creative journey Frontline, Volume 20 - Issue 05, 01 - 14 March 2003.

[2] Knowles, Pat (2007). "Obituary: Laurie Baker: pioneering architect". The Friend: 18-19.

[3] Bhatia 2003, p. 8.

[4] Bhatia 2003, p. 9.

[5] Bhatia 2003, p. 10.

[6] Bhatia 2003, p. 15.

[7] Kuriakose, Benny (2007). "Laurie Baker- the unseen side..." (PDF). Architecture and Design: 3442

[8] Low cost housing manual (pdf).

[9] baker-japan.(pdf)

[10] manual of cuts cost for strong acceptable housing, (pdf)

[11] Cost ford. Built in live, htm.

[12] Low cost sustainable housing(Eng.)2010.(pdf)

*Corresponding authors.

E-mail address: manitasaxena450@gmail.com 